\title{
THE INFLUENCE OF HEAT TREATMENTS ON THE MECHANICAL PROPERTIES OF RESISTANCE SPOT WELDED JOINTS FROM NIMONIC 80 A ALLOYS
}

\author{
Lucian BURCĂ ${ }^{1}$, Ion MITELEA ${ }^{1}$, Mircea BURCĂ ${ }^{1}$, Ion-Dragos UŢU1', \\ Corneliu Marius CRĂCIUNESCU ${ }^{1}$ \\ ${ }^{1}$ University Politehnica Timisoara, Pta Victoriei, Timisoara, Romania, EU, \\ lucian.burca@studen.upt.ro, ion.mitelea@upt.ro,.dragos.utu@upt.ro, cornliu.craciunescu@upt.ro
}

https://doi.org/10.37904/metal.2021.4134

\begin{abstract}
The resistance spot welding of the Nimonic alloys is a critical technology by manufacturing of components used for nuclear and aeronautical industry, as well as for the chemical and the petro-chemical domain. The mechanical properties and the corrosion resistance can be affected by the heat - mechanical shock caused by the welding cycle. The present paper reveals the positive effect of the heat treatment, applied before and after welding process, on the mechanical properties of the welded joints. Destructive tensile tests, shearing stress measurements and metallographic investigations were performed to evaluate the quality of the welded joints.
\end{abstract}

Keywords: Heat treatment, Nimonic 80 A alloy, mechanical tests, resistance spot welding

\section{INTRODUCTION}

The Nimonic 80 A alloys are part of the materials hardened by aging heat treatment and are used in the gas turbine construction and for parts which are working in significant thermal conditions from the nuclear or automobile industry. Their exploitation properties depends on the type, quantity and the distribution of the precipitate phases, of the dislocation structure and the dimension of the grains and sub-grains $[1,2]$. The crystal lattice of the solid solution $\gamma$ matrix is cubic face-centred, a property that provides good deformability characteristics. When welding these materials, three main difficulties appear $[3,4,6]$ :

- deterioration of the mechanical characteristics of the heat affected zone after welding;

- $\quad$ cracking at reheating;

- $\quad$ hot cracking in the partial melted area.

A fundamental role in avoiding or minimizing these events have the heat treatments applied before or after the welding operation. The present work proposed some heat treatments specific for spot welding of sheets with the thickness of $1.6 \mathrm{~mm}$.

\section{EXPERIMENTAL PROCEDURES}

\subsection{Welding and heat treatments}

The sheets with the thickness of $1.6 \mathrm{~mm}$ of Nimonic 80 A alloy material were welded by resistance spot process in order to determine the optimal parameters that gives a technological process that is reliable and repeatable, resulting a superior quality of the welding [6]. The validation of these parameters was done by mechanical tensile and de-buttoning tests followed by metallographic investigations to reveal the welded nucleus, Figure 1, and their fracture behavior. The optimal values of the technologic parameters are shown below:

- $\quad$ welding current: Is $=5.5-6.2 \mathrm{kA}$; 
- $\quad$ welding time: $t_{s}=15-20 p ;(1 p=0.02 s)$;

- $\quad$ pressing force: $\mathrm{F}_{\mathrm{ap}}=430-470 \mathrm{daN}$;

- $\quad$ equipment electrode diameter: $d_{e}=6.0-6.5 \mathrm{~mm}$;

- $\quad$ current density: $\mathrm{j}=180-215 \mathrm{~A} / \mathrm{mm}^{2}$;

- $\quad$ specific pressure: $p=135-160 \mathrm{~N} / \mathrm{mm}^{2}$.

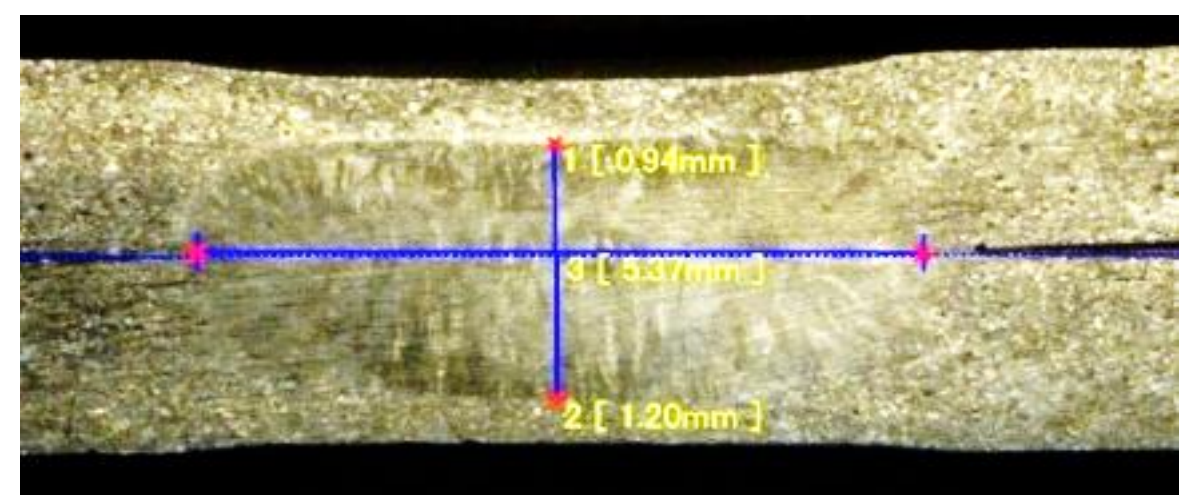

Figure 1 The macroscopic aspect of the welded joint

Some samples were welded joint without a heat treatment and others were heat treated before and after the welding process. These heat treatments were performed in an oven Therma V22, presented in Figure 2.
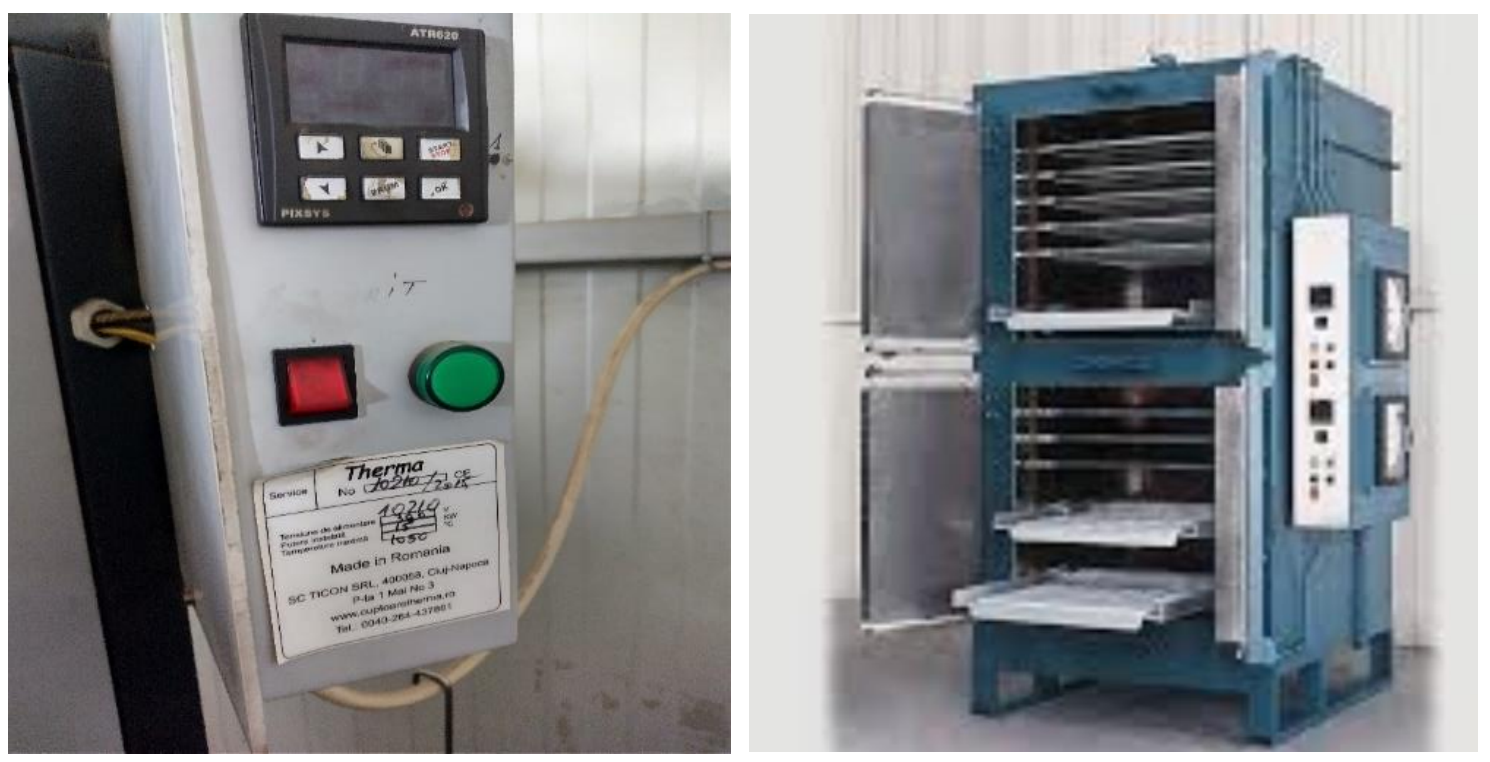

Figure 2 Industrial heating oven, THERMA V22

Before welding a solution treatment was applied consisting of a heating at $1150^{\circ} \mathrm{C}$ for two minutes followed by cooling in air, these having as purpose to obtain a recrystallization of the rough structure, a dissolving of the secondary phases and a reduction of the internal stresses. The heat cycle of the heat treatment is presented in Figure 3.

The next step was the welding of the sheets. Some of the samples were not heat-treated and some were solution treated according to Figure 3 diagram. After the solution treatment, the surface of the samples was covered with a nickel oxide layer, very compact and adherent, of green color, very hard to be mechanically removed. To avoid its influence on the welding process it was removed by polishing with a fine rough disc, on 
both contact surfaces in the area that was supposed to be welded. The used technological parameters are present in Table 1.

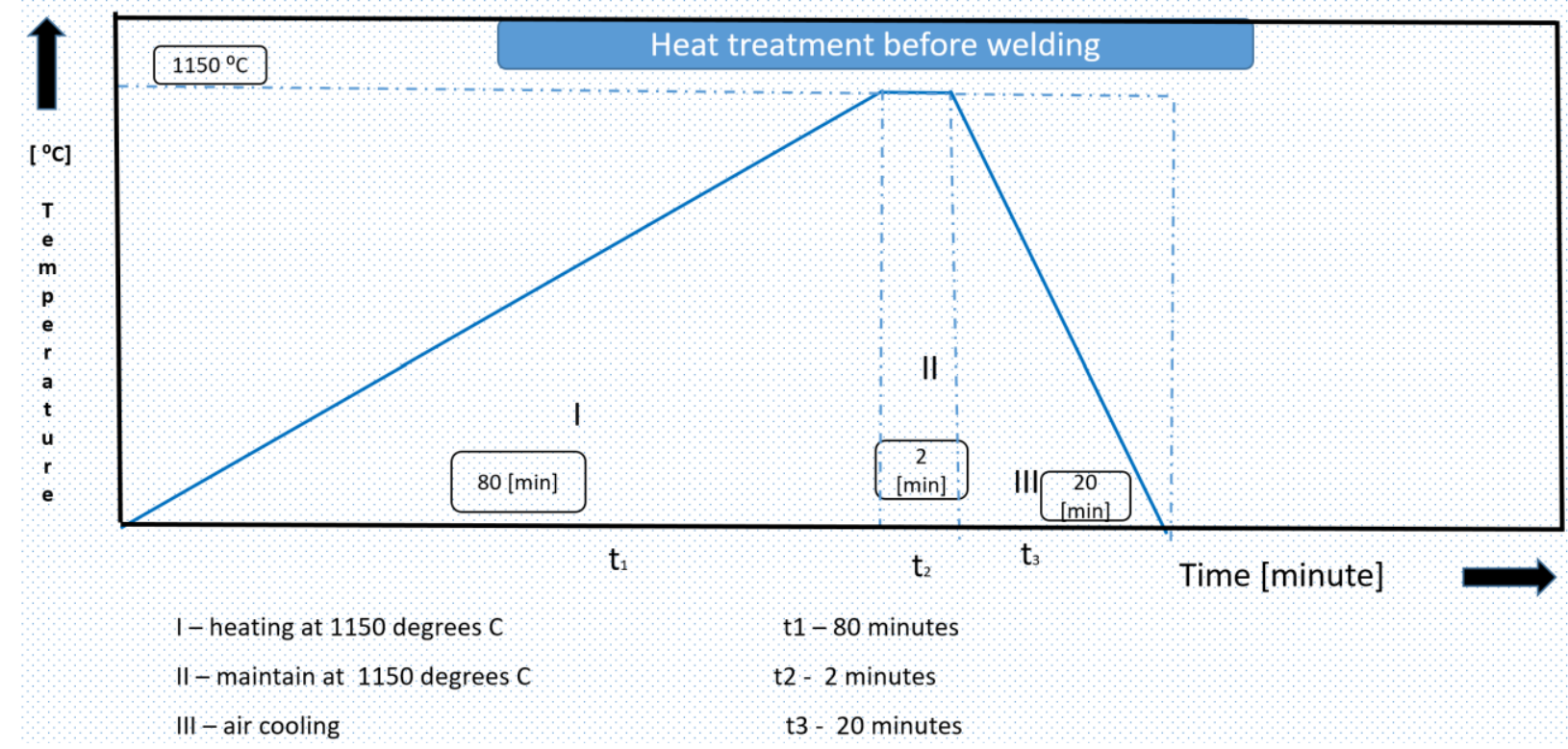

Figure 3 Thermal cycle diagram of the solution treatment

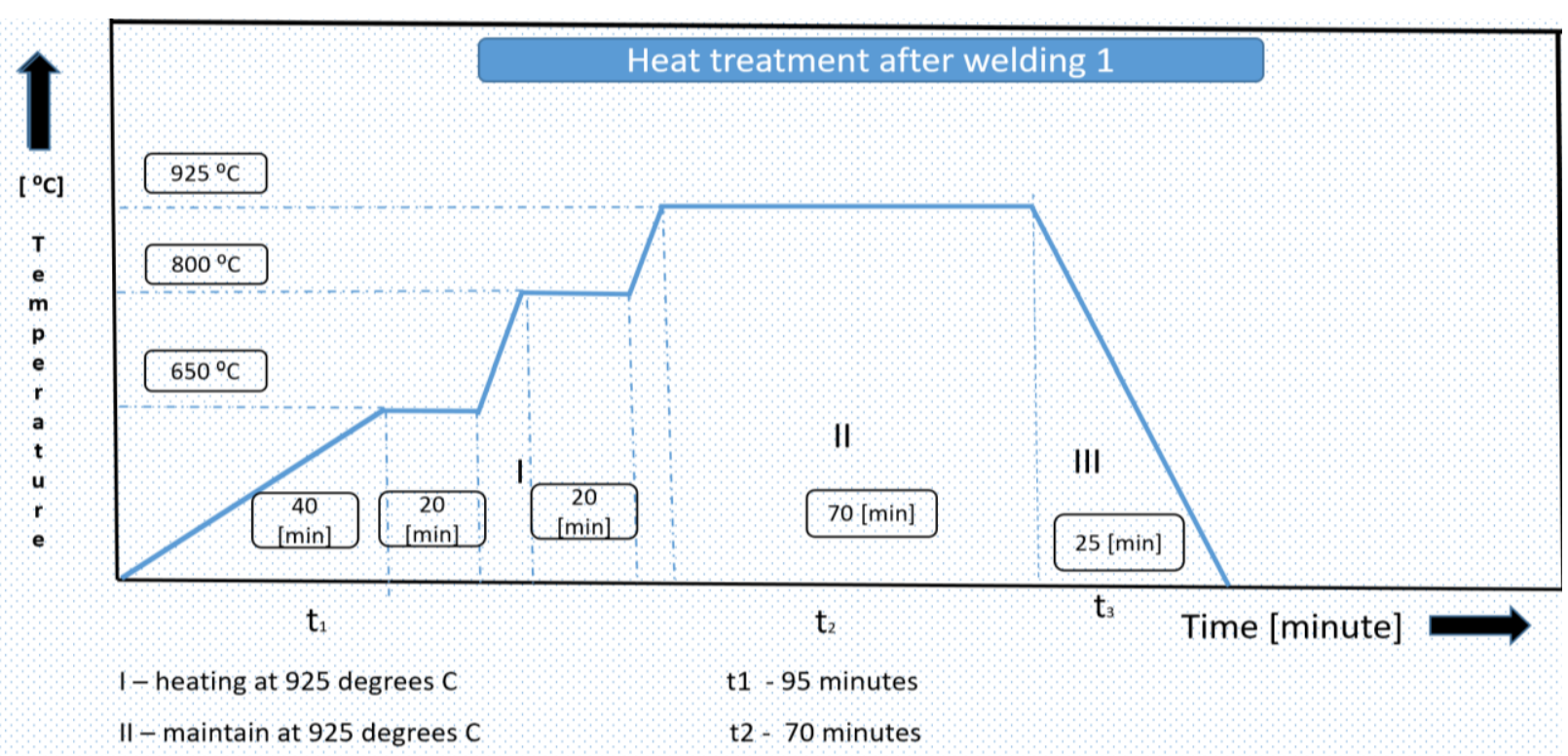

Figure 4 The thermal cycle diagram of the primary aging treatment

Table1 The welding parameters

\begin{tabular}{|c|c|c|}
\hline Current, $\mathbf{k A}$ & Voltage, $\mathbf{U}$ & Cycle time, $\mathbf{p}=\mathbf{0 . 0 2} \mathbf{~ s}$ \\
\hline 5.8 & 0.94 & 15 \\
\hline
\end{tabular}

The heat treatment applied after welding consisted in a solution treatment, at the values from Figure 3 , followed by a double aging treatment, first one at $925^{\circ} \mathrm{C}$ with 70 minutes maintaining and cooling in air (Figure 4), and the second, at $750^{\circ} \mathrm{C}$ with 240 minutes maintaining and cooling in the air (Figure 5). These 
heat treatments followed the microstructure recrystallization of welded zones and an improvement of the mechanical properties.

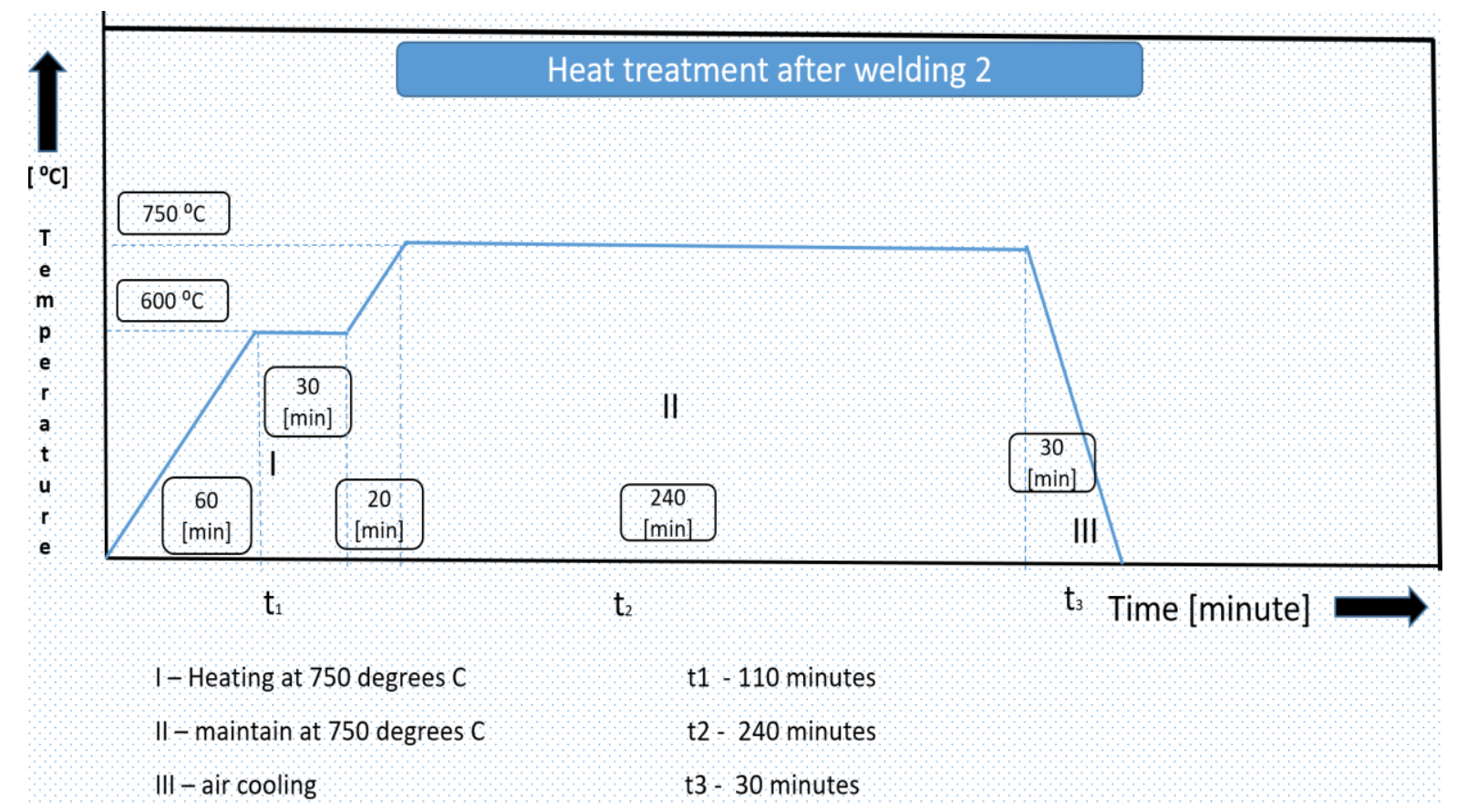

Figure 5 The thermal cycle diagram of the secondary aging treatment

\subsection{Mechanical tensile destructive tests}

In Figure 6 can be seen some examples of welded samples obtained by the used joining technology.
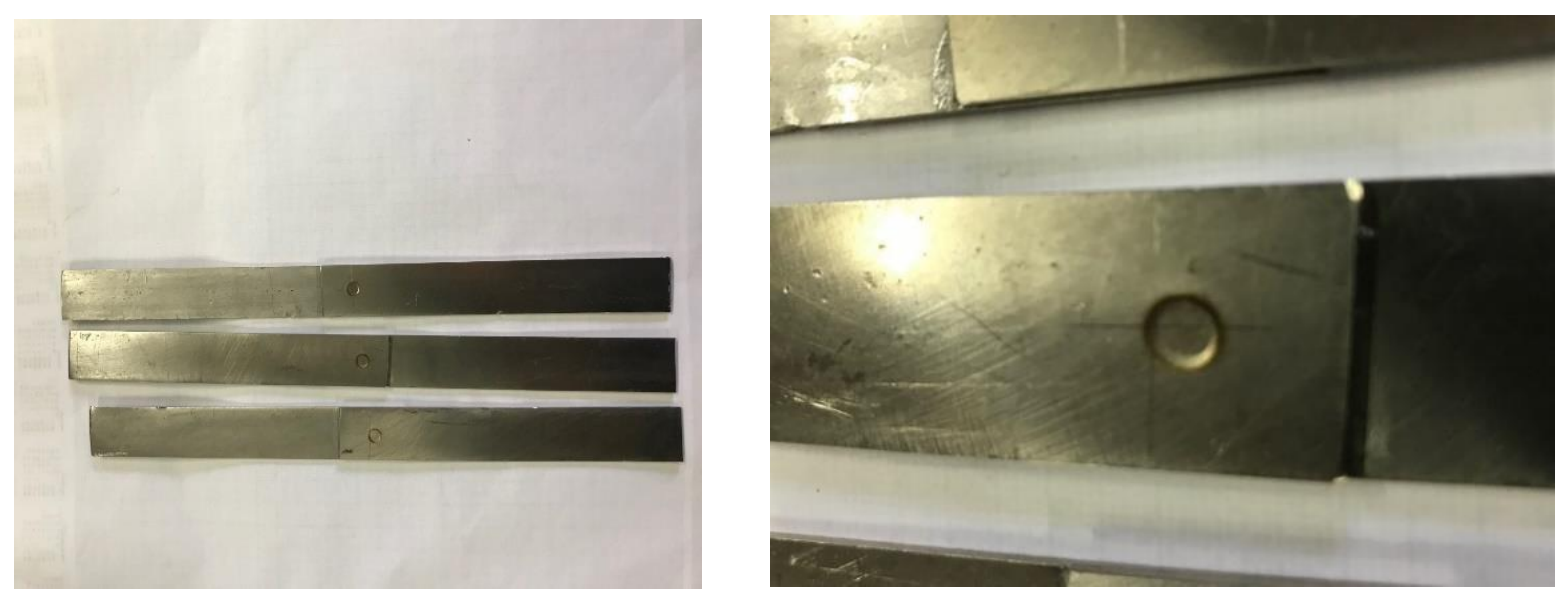

Figure 6 The aspect of the welded samples (detailed welding point)

The experimental shear tests of the spot welded joints were realized with the Zwick/Roell equipment, of 250 $\mathrm{kN}$. The testing temperature was $18^{\circ} \mathrm{C}$. The samples were placed on the device with the help of the hydraulic fixing elements at a distance of $110 \mathrm{~mm}$, this being the reference distance of the deformation. The measurements were done at a speed of $0.1 \mathrm{~mm} /$ minute, the force being registered by the measuring device that has a precision rate of $0.1 \%$. The recorded deformation was taken as a displacement of the transverse beam of the testing equipment. [5] 
In Figure 7 there are presented the force-deformation diagram for the welded Nimonic 80A sheets with and without the heat treatment. In all cases the fracture took place is in the welded nugget (nucleus) and it is determined by its shear under the tensile-shear force.

Figure 8 presents the macroscopic aspect of a sample treated and not heat treated after the tensile-shear test. The obtained results are presented in Table 2. It can be observed that by the samples that are not heat treated the tensile strenght is at $10000 \mathrm{~N}$ and the shear stress is at $390 \mathrm{MPa}$; by the heat treated samples the tensile strenght increases at $12000 \mathrm{~N}$ and the shear shear at $530 \mathrm{Mpa}$.

Table 2 Results of the tensile-shear measurements

\begin{tabular}{|c|c|c|c|c|c|c|}
\hline \multirow[b]{2}{*}{ Structural phase } & \multirow{2}{*}{$\begin{array}{l}\text { Samples size } \\
\text { L x b x s, mm }\end{array}$} & \multirow{2}{*}{$\begin{array}{c}\text { Force } \\
\text { Fmax., }_{\text {max }}\end{array}$} & \multirow{2}{*}{$\begin{array}{c}\text { Elongation } \\
\text { max. } \\
\text { mm }\end{array}$} & \multicolumn{2}{|c|}{ Nugget Diameter } & \multirow{2}{*}{$\begin{array}{c}\text { Shear tension } \\
\text { Zf, MPa }\end{array}$} \\
\hline & & & & $\mathrm{d}_{\mathrm{n}}, \mathrm{mm}$ & $\mathrm{A}, \mathrm{mm}^{2}$ & \\
\hline Samples not heat treated & $400 \times 22.5 \times 1.55$ & 10429 & 1.018 & 5.8 & 26.40 & 395 \\
\hline $\begin{array}{c}\text { Samples with heat } \\
\text { treatment }\end{array}$ & $400 \times 22.5 \times 1.55$ & 12192 & 0.765 & 5.4 & 22.89 & 532 \\
\hline
\end{tabular}

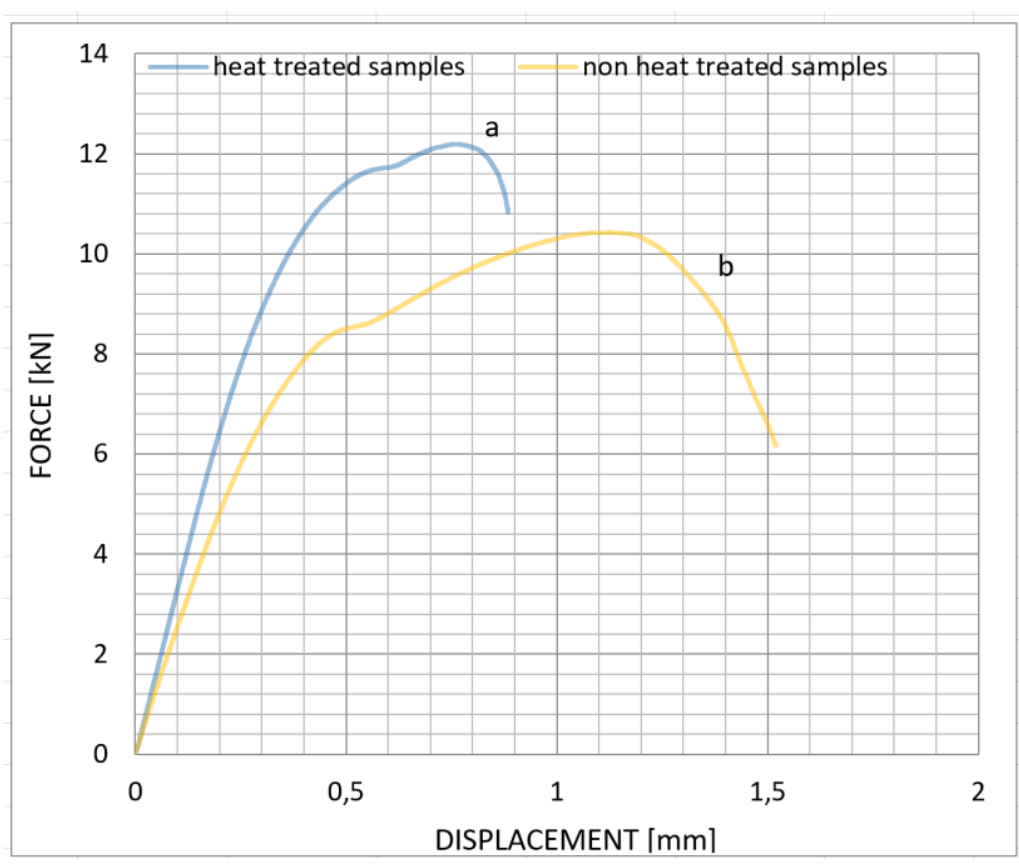

Figure 7 Tensile diagrams $F=f(\Delta L): a-$ samples not heat treated; $b-$ samples heat treated

Figure $\mathbf{8}$ presents the macroscopic aspect of the fractured samples. In all cases the rupture took place by shear in the welded point.

a)

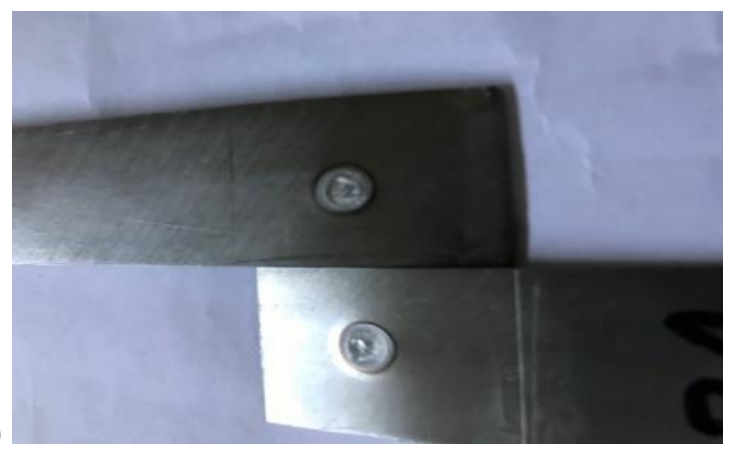

b)

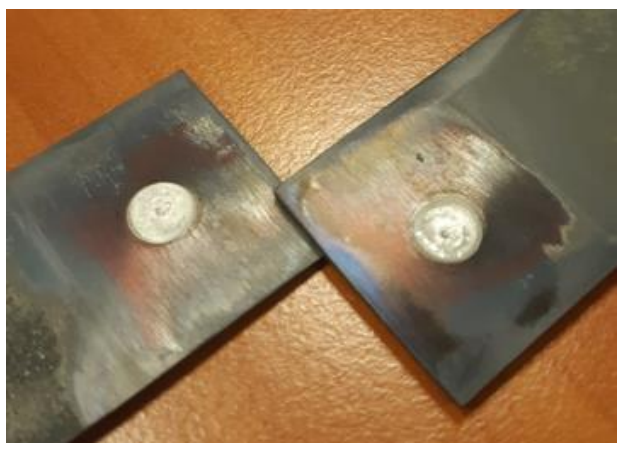

Figure 8 Aspect of the samples fracture (detail) a- not heat treated; b-heat treated 
The examination of the fractured surface of the welding nugget using electronic microspcopy shows that even if the applied heat treatments decreases the ellongation, the plastical reserve of the welded joint remains high, meaning a ductile behavior which is preceeded by a larger plastical deformation (seen in Figure 9 ).

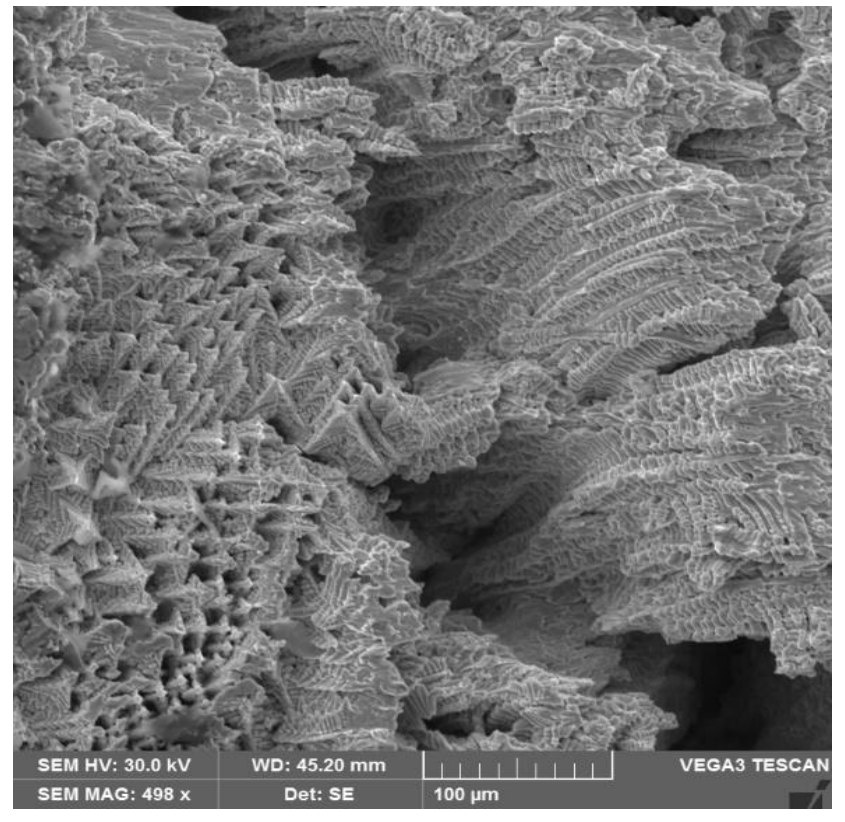

$-a-$

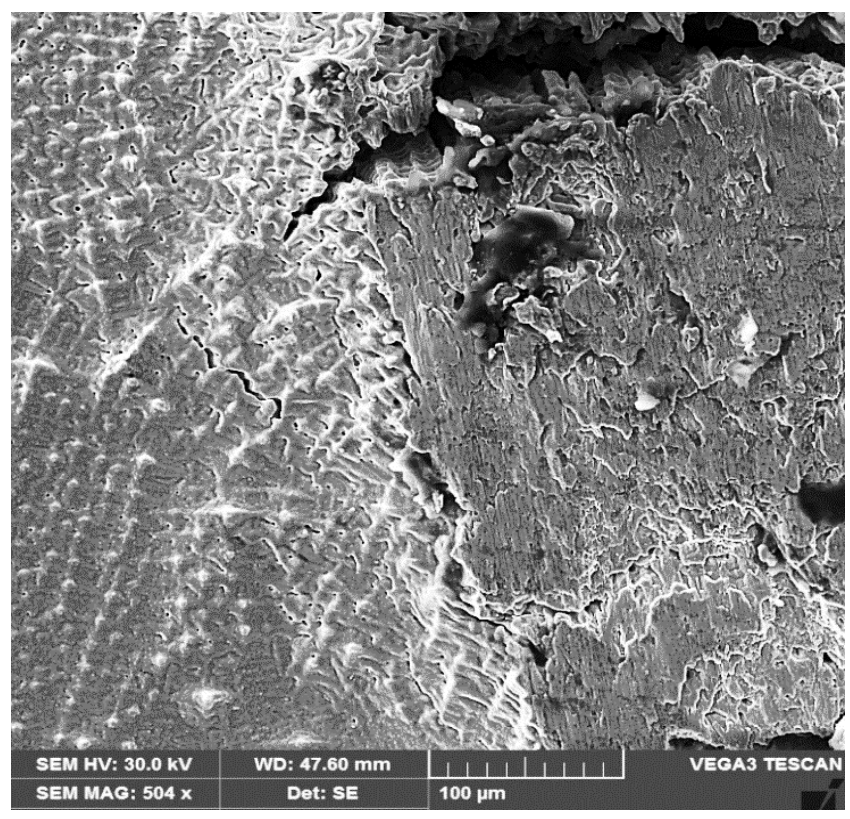

$-b-$

Figure 9 SEM micrograph, $x$ 500, of the fracture surface on the welding nugget $a-$ without heat treatment; $\mathrm{b}$ - with heat treatment

\section{CONCLUSION}

The heat treatments applied after the welding of Nimonic $80 \mathrm{~A}$ alloys provides a significative improvement on the mechanical resistance characteristics of the welded joints ( the shear stress increases with $37 \%$ ).

The fracture of the welded samples takes place in the welded nucleus and it is determined mainly by shear phenomen produced under the tensile-shear force.

The metalographic examination of the fracture surfaces highlights the presence of a large number of ductile cleavage steps and cracks that branches forming a "river spectrum".

\section{REFERENCES}

[1] POLLOCK, TM. Alloy design for aircraft engines. Nat. Mater. 2016, vol.15, pp. 809-815.

[2] DAVID, S.A., SIEFERT, J.A., DUPONT, J.N., et al. Weldability and weld performance of candidate nickel base superalloys for advanced ultra supercritical fossil power plants part I: fundamentals. Sci Technol Weld Join. 2015, vol. 20, pp. 532-552.

[3] DUPONT, J.N., LIPPOLD, J.C., KISER S.D. Welding metallurgy and weldability of nickel alloys. Hoboken (NJ): Wiley; 2005.

[4] HENDERSON, M.B., ARRELL, D., HEOBEL. M, et al. Nickel based superalloy welding practices for industrial gas turbine applications. Sci Technol Weld Join. 2004, vol.9, pp.13-21.

[5] UNGUREANU, V., BOTH, I., BURCA, M., RADU, B., NEAGU, C., DUBINA., D. Experimental and numerical investigations on built-up cold-formed steel beams using resistance spot welding. Thin-Walled Structures. 2021, vol. 161.

[6] BURCA, C.L., MITELEA, I., UTU, I.D., BURCA, M. Resistance Spot Welding Process Particularities of the Nickel Alloy Nimonic 80 A. In: Materials Today: Proceedings. 2021, article in press. 